\title{
SYNTHESIS OF NOVEL AROMATIC NITROXIDES AS POTENTIAL DNA INTERCALATORS. AN EPR SPECTROSCOPICAL AND DFT COMPUTATIONAL STUDY
}

\author{
Mario Beyer, Jörg Fritscher, Emiliano Feresin, Olav Schiemann* \\ Institut für Physikalische und Theoretische Chemie, Johann Wolfgang Goethe- \\ Universität, Marie-Curie-Straße 11, D-60439 Frankfurt am Main, Germany \\ * Corresponding author. E-mail: o.schiemann@ prisner.de
}

\section{Supporting Information}

Table of Contents:

Total energies and optimized cartesian coordinates for compounds $\mathbf{1}^{\bullet}, \mathbf{2}^{\bullet}, \mathbf{3}^{\bullet}, \mathbf{4}^{\bullet}$ and $\mathbf{5}^{\bullet}$ as obtained from unrestricted PBE0/6-31G(d) computations. 


\section{Carbazol-9-oxyl 1.}

Energy $=-591.34421 \mathrm{E}_{\mathrm{h}}$

$\begin{array}{lrrr}\mathrm{C} & -0.7446454857 & 0.4955746722 & -0.5177236234 \\ \mathrm{C} & -1.1251768303 & -0.4268788487 & 0.4750396856 \\ \mathrm{~N} & 0.0309108599 & -0.9785814226 & 1.0465183037 \\ \mathrm{C} & 1.1516636818 & -0.4119652016 & 0.4217347545 \\ \mathrm{C} & 0.7130510808 & 0.5051147857 & -0.5518597958 \\ \mathrm{C} & 2.4887069923 & -0.6721232063 & 0.6778389381 \\ \mathrm{C} & 3.420099065 & 0.0264044095 & -0.0846207273 \\ \mathrm{C} & 3.0126359809 & 0.9449040006 & -1.0602142139 \\ \mathrm{C} & 1.6619868518 & 1.1919092628 & -1.3020737214 \\ \mathrm{C} & -1.7365573342 & 1.1696785087 & -1.2224848978 \\ \mathrm{C} & -3.0710578871 & 0.9051035764 & -0.9177537373 \\ \mathrm{C} & -3.4203668258 & -0.0183583439 & 0.0755512733 \\ \mathrm{C} & -2.4452506497 & -0.7044219786 & 0.7933554912 \\ \mathrm{O} & 0.0580934916 & -1.8393736497 & 1.9667977142 \\ \mathrm{H} & 2.774520224 & -1.3891823874 & 1.4400949453 \\ \mathrm{H} & 4.4802118252 & -0.1437166147 & 0.0798349695 \\ \mathrm{H} & 3.763642723 & 1.4746738457 & -1.6392117269 \\ \mathrm{H} & 1.3603656092 & 1.9073011756 & -2.0622535445 \\ \mathrm{H} & -1.480217111 & 1.8887153335 & -1.9957319874 \\ \mathrm{H} & -3.8552055612 & 1.4248315633 & -1.4608020118 \\ \mathrm{H} & -4.4693025221 & -0.2022732186 & 0.2894039935 \\ \mathrm{H} & -2.6856709794 & -1.4249403622 & 1.5679189672\end{array}$




\section{9,9-Diphenylacridan-10-oxyl $2^{\circ}$.}

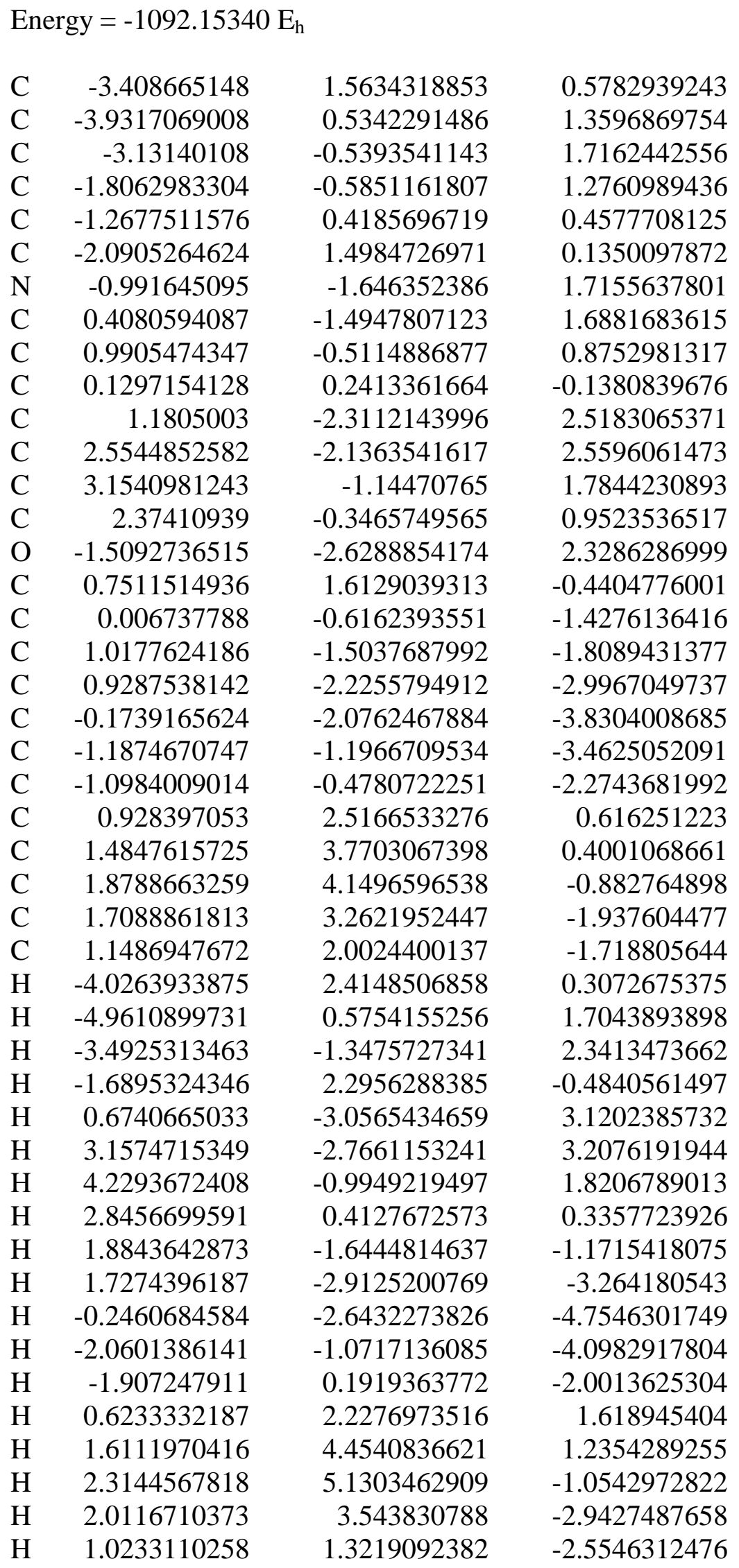




\section{3,6-Dimethylcarbazol-9-oxyl 3.}

Energy $=-669.88251 \mathrm{E}_{\mathrm{h}}$

$\begin{array}{rrrr}\mathrm{C} & -0.5689977627 & 0.4208544941 & -0.3907409632 \\ \mathrm{C} & -1.3574320482 & -0.098760055 & 0.6502467957 \\ \mathrm{~N} & -0.5515850407 & -0.8885187848 & 1.4823447742 \\ \mathrm{C} & 0.7552853441 & -0.8755713289 & 0.9745499027 \\ \mathrm{C} & 0.7865720942 & -0.0764356104 & -0.1841648382 \\ \mathrm{C} & 1.8751634541 & -1.5165692523 & 1.4755515236 \\ \mathrm{C} & 3.0661697869 & -1.3406818918 & 0.7771484145 \\ \mathrm{C} & 3.142642802 & -0.5527559582 & -0.3826622529 \\ \mathrm{C} & 1.9887499408 & 0.0814182919 & -0.860653604 \\ \mathrm{C} & -1.1658195624 & 1.2398851111 & -1.3437953991 \\ \mathrm{C} & -2.529597872 & 1.5305774589 & -1.2513320759 \\ \mathrm{C} & -3.281809679 & 0.9886925681 & -0.192211984 \\ \mathrm{C} & -2.7125325174 & 0.1683198446 & 0.7732067077 \\ \mathrm{C} & 4.4487564081 & -0.3874716195 & -1.1104879815 \\ \mathrm{C} & -3.1975783663 & 2.4145639676 & -2.2682147413 \\ \mathrm{O} & -0.9367216053 & -1.5055089051 & 2.5121895033 \\ \mathrm{H} & 1.8099299864 & -2.1239831521 & 2.3721306146 \\ \mathrm{H} & 3.9680470218 & -1.828047461 & 1.1391505662 \\ \mathrm{H} & 2.0412352669 & 0.6933672511 & -1.7586412761 \\ \mathrm{H} & -0.579509201 & 1.6554100044 & -2.1601300831 \\ \mathrm{H} & -4.3424274613 & 1.2213212301 & -0.1304411408 \\ \mathrm{H} & -3.2859599414 & -0.2530546284 & 1.5922113083 \\ \mathrm{H} & 4.3816079193 & -0.757999384 & -2.1404264609 \\ \mathrm{H} & 5.2553430076 & -0.9335826834 & -0.6126835372 \\ \mathrm{H} & 4.7445689502 & 0.6669787478 & -1.1657697383 \\ \mathrm{H} & -3.6260216918 & 3.3086040587 & -1.799399746 \\ \mathrm{H} & -4.0182305887 & 1.8917571307 & -2.7737950868 \\ \mathrm{H} & -2.4911472731 & 2.7465354984 & -3.0347718912\end{array}$




\section{9-Acridanylidenmalonitrile-10-oxyl $4^{\circ}$.}

$\begin{array}{lrrr}\text { Energy }=-852.92182 \mathrm{E}_{\mathrm{h}} & & \\ \mathrm{C} & -3.5425717827 & -0.8260620729 & -0.5715645832 \\ \mathrm{C} & -3.477292461 & -1.7108682654 & 0.5096186793 \\ \mathrm{C} & -2.287176604 & -1.888398138 & 1.1879693478 \\ \mathrm{C} & -1.1560086921 & -1.1670785788 & 0.7924281089 \\ \mathrm{C} & -1.2119335607 & -0.2119867066 & -0.2473654944 \\ \mathrm{C} & -2.4307761529 & -0.088446762 & -0.93814478 \\ \mathrm{~N} & 0.0534511306 & -1.4297237061 & 1.4456799349 \\ \mathrm{C} & 1.2553823289 & -0.9841843987 & 0.8841490491 \\ \mathrm{C} & 1.2451544426 & -0.0256047158 & -0.1538794683 \\ \mathrm{C} & -0.0240229913 & 0.5864476794 & -0.5383825433 \\ \mathrm{C} & 2.4491618827 & -1.5292059534 & 1.368012408 \\ \mathrm{C} & 3.6467252784 & -1.1705833245 & 0.7803879726 \\ \mathrm{C} & 3.6594153408 & -0.2798598733 & -0.2978299267 \\ \mathrm{C} & 2.4800777755 & 0.2840005916 & -0.7514521293 \\ \mathrm{C} & -0.1019081344 & 1.8718877106 & -1.0526454545 \\ \mathrm{C} & 1.0224472647 & 2.7282047719 & -1.2460052544 \\ \mathrm{~N} & 1.8911336057 & 3.4824223307 & -1.4194090534 \\ \mathrm{C} & -1.3243895608 & 2.5499791143 & -1.3363992327 \\ \mathrm{~N} & -2.2810320572 & 3.1653426318 & -1.5807230621 \\ \mathrm{O} & 0.071784326 & -2.1813238565 & 2.4630730028 \\ \mathrm{H} & -4.4657797236 & -0.7128831366 & -1.1311977879 \\ \mathrm{H} & -4.3547007821 & -2.2781226328 & 0.805642654 \\ \mathrm{H} & -2.1879771163 & -2.5872830819 & 2.0095813801 \\ \mathrm{H} & -2.5022130182 & 0.5796204469 & -1.7866917049 \\ \mathrm{H} & 2.3946584922 & -2.2397810224 & 2.1837564252 \\ \mathrm{H} & 4.5746735572 & -1.6009568112 & 1.1450029299 \\ \mathrm{H} & 4.5946103679 & -0.0257540274 & -0.7868593816 \\ \mathrm{H} & 2.5138786186 & 0.9600158514 & -1.5960334655\end{array}$




\section{9-Ethylacridanylidenecyanoacetate-10-oxyl $5^{\circ}$.}

$\begin{array}{lrrr}\text { Energy }=-1027.68251 \mathrm{E}_{\mathrm{h}} & & \\ \mathrm{C} & 1.8850419409 & 2.3653472342 & -1.4803565348 \\ \mathrm{C} & 1.203037584 & 3.4337227427 & -0.8872510221 \\ \mathrm{C} & 0.0231001806 & 3.2100475269 & -0.2031084588 \\ \mathrm{C} & -0.4697156661 & 1.9053524044 & -0.0932823696 \\ \mathrm{C} & 0.2422424236 & 0.8029938444 & -0.6045100915 \\ \mathrm{C} & 1.408717035 & 1.0731037138 & -1.3382712136 \\ \mathrm{~N} & -1.7166826661 & 1.7093563012 & 0.5121696758 \\ \mathrm{C} & -2.3977699955 & 0.4984969566 & 0.3149471348 \\ \mathrm{C} & -1.7198998425 & -0.6311851926 & -0.1960441677 \\ \mathrm{C} & -0.266670822 & -0.5507115262 & -0.3739403024 \\ \mathrm{C} & -3.760945846 & 0.4569239624 & 0.62333874 \\ \mathrm{C} & -4.4804078333 & -0.6964879861 & 0.3740766528 \\ \mathrm{C} & -3.8475856843 & -1.8071353842 & -0.1907585824 \\ \mathrm{C} & -2.4901986121 & -1.7738591135 & -0.4652253936 \\ \mathrm{O} & -2.2915746201 & 2.6725515605 & 1.1000935863 \\ \mathrm{C} & 0.5823929969 & -1.6258628272 & -0.2759024875 \\ \mathrm{C} & 2.0852039183 & -1.5238470601 & -0.2554363178 \\ \mathrm{C} & 0.1594461085 & -2.9715497284 & -0.109294421 \\ \mathrm{~N} & -0.1169030254 & -4.092312339 & 0.0423281346 \\ \mathrm{O} & 2.8102589265 & -2.1147558902 & -1.0198248933 \\ \mathrm{O} & 2.5029622683 & -0.7495810851 & 0.7467601851 \\ \mathrm{C} & 3.9262644101 & -0.5608664948 & 0.829063002 \\ \mathrm{C} & 4.1928446689 & 0.3363219797 & 2.0127369151 \\ \mathrm{H} & 2.7827193537 & 2.5462306377 & -2.0639601521 \\ \mathrm{H} & 1.581099158 & 4.4467539854 & -0.9891978472 \\ \mathrm{H} & -0.5545421855 & 4.015452031 & 0.2343136506 \\ \mathrm{H} & 1.9278952411 & 0.2564877457 & -1.830366991 \\ \mathrm{H} & -4.2198113265 & 1.3476984479 & 1.0350654859 \\ \mathrm{H} & -5.5419336766 & -0.7278021524 & 0.6013507624 \\ \mathrm{H} & -4.4153512072 & -2.7042735944 & -0.4175330852 \\ \mathrm{H} & -2.0224925494 & -2.6439392505 & -0.907700998 \\ \mathrm{H} & 4.2729729792 & -0.117728344 & -0.1110848184 \\ \mathrm{H} & 4.4041877265 & -1.5402592661 & 0.9295878206 \\ \mathrm{H} & 5.2692402742 & 0.5091075008 & 2.1117771626 \\ \mathrm{H} & 3.830790287 & -0.120902198 & 2.9383235143 \\ \mathrm{H} & 3.6965713778 & 1.3033197278 & 1.8870233053\end{array}$

